\title{
Influential Factors of Water Scarcity in Xinjiang
}

\author{
Lang Liu \\ School of North China Electric Power University, BaoDing 471000,China \\ 1182715929@qq.com
}

Keywords: water scarcity influence index Physical and Economic scarcity average sensitivity index

\begin{abstract}
Firstly, we define $\mathrm{Z}$ as the index measuring the ability of one region to meet its water demand. Next, We define $\beta$ to represent thedegree of how these factors influence Index $Z$ by using weight and correlation coefficient. Afterwards we accordingly work out the most influential factors causing water scarcity there, theyare cultivated land, internal groundwater/surface water and policy on water dispatch. Last but not least, we introduce a concept of average sensitivity index. Everysingle factor has a corresponding average sensitivity index. The higher the index is, the moreinfluential of this factor to index $\mathrm{Z}$. By substituting concrete data into calculation, we findvariation trend of average sensitivity index agree with $\beta$.
\end{abstract}

\section{Introduction}

Water scarcity is the lack of sufficient available water resources to meet water needs within a region. The cause of water scarcity is rather complicated. Generally, these drivers are classified into two categories: physical scarcity and economic scarcity. Physical scarcity, also known as absolute scarcity, simply means natural limitation of water resources, usually refers to those natural drivers for scarcity. Economic scarcity, on the other hand, means the scarcity resulting from lack of investment in infrastructure when there are sufficient water resources in one region, usually refers to human factors. Solving world water problem is an urgent task facing any government, institution and individual.

\section{Analysis in Chosen Area}

\subsection{Determining Evaluation factors}

The ability of a region to provide its people with clean water is dependent on various factors from different aspects like social facet, ecological facet, economic facet and so on. We determine the following factors as important ones and sort out these factors into four categories[1].

Table 1: Evaluation factors from different scales

\begin{tabular}{|c|l|c|}
\hline \multirow{5}{*}{$\begin{array}{c}\text { Physical } \\
\text { availability }\end{array}$} & Long-term average precipitation in volume & $\mathrm{Y}_{1}$ \\
\cline { 2 - 3 } & Surface water produced internally & $\mathrm{Y}_{2}$ \\
\cline { 2 - 3 } & Groundwater produced internally & $\mathrm{Y}_{3}$ \\
\cline { 2 - 3 } & Total internal renewable water and groundwater(IRWR) & $\mathrm{Y}_{4}$ \\
\cline { 2 - 3 } & Technological advances & $\mathrm{Y}_{5}$ \\
\cline { 2 - 3 } & National Rainfall Index(NRI) & $\mathrm{Y}_{6}$ \\
\hline \multirow{5}{*}{ Socio-economy } & Industrial output & $\mathrm{Y}_{7}$ \\
\cline { 2 - 3 } & Cultivated area & $\mathrm{Y}_{8}$ \\
\cline { 2 - 3 } & $\begin{array}{l}\text { Total amount of wastewater produced by agriculture, industry and } \\
\text { domestic. }\end{array}$ & $\mathrm{Y}_{9}$ \\
\cline { 2 - 3 } & Gross Domestic Product (GDP) & $\mathrm{Y}_{10}$ \\
\cline { 2 - 3 } & Human Development Index (HDI) & $\mathrm{Y}_{11}$ \\
\hline \multirow{5}{*}{ Population } & Total population & $\mathrm{Y}_{12}$ \\
\cline { 2 - 3 } & Water consumption per capita & $\mathrm{Y}_{13}$ \\
\cline { 2 - 3 } & Rural population/urban population & $\mathrm{Y}_{14}$ \\
\hline \multirow{5}{*}{ Policy } & Water dispatch between regions & $\mathrm{Y}_{15}$ \\
\cline { 2 - 3 } & Water price & $\mathrm{Y}_{16}$ \\
\hline
\end{tabular}


We define $\mathrm{Z}$ as the index measuring the ability of one region to meet its water demand. The index showing to what extent the region is capable of meeting the water demand of its population. The higher of $\mathrm{Z}$ is, the stronger ability of a region is. The smaller the $\mathrm{Z}$ is, the more likely is for a region to have water scarcity.

We analyze these factors to see whether their impact on index $\mathrm{Z}$ is positive or negative for the convenience of data pre-processing.

\subsection{Choosing an area_the Xinjiang Province in China}

In order to study region specifically to dig deep about the causes of its water scarcity, we pick one region which is moderately exploited_ _ the Xinjiang Province in China[2].

Xinjiang Province lies in the Northwest of China. It has a semi-arid or desert climate. It has a vast area of 1.66 million square kilometers while relatively small population. Xinjiang has long been a major area of irrigated agriculture.

\subsection{Deciding most Influential factors causing water scarcity}

In order to analyze quantitatively the impact of different factors on the index Z, we model on figuring out how the detailed factors $Y_{1-16}$ affect index Z[3].

We define $\beta_{k}$ as the degree of how $Y_{k}$ influence the index $Z$. We choose the first 3 principle components that have the highest accumulative contribution rate in categories $\mathrm{X}_{1-3}$. In category $\mathrm{X}_{4}$ there are only two factors, we use the following equations to calculate $\beta$ for each factor.

$$
\begin{gathered}
\beta_{k}=\left(\mathrm{u}_{k 1} \mathrm{w}_{k 1}+\mathrm{u}_{k 2} \mathrm{w}_{k 2}+\mathrm{u}_{k 3} \mathrm{w}_{k 3}\right) \cdot \mathrm{p}_{i} \quad i=1,2,3 \quad k=1,2 \ldots 14 \\
\beta_{k}=\left(\mathrm{u}_{k 1} \mathrm{w}_{k 1}+\mathrm{u}_{k 2} \mathrm{w}_{k 2}\right) \bullet \mathrm{p}_{i} \quad i=4 \quad k=15,16
\end{gathered}
$$

In this way we can get the final value of $\beta$, represents the importance of these factors in deciding index Z. Depending on this, we are able to find the most influential factors in one region that cause water scarcity in a quantitative way.

\subsection{Deciding Influential factors of water scarcity in Xinjiang}

After we have established a quantitative method to find the most influential factors in causing water stress, we gathered data of these 16 factors from National Bureau Statistics of China, dated from 2002 to 2014. We substitute this data into the model to see which factor influences the Index Z the most in Xinjiang.

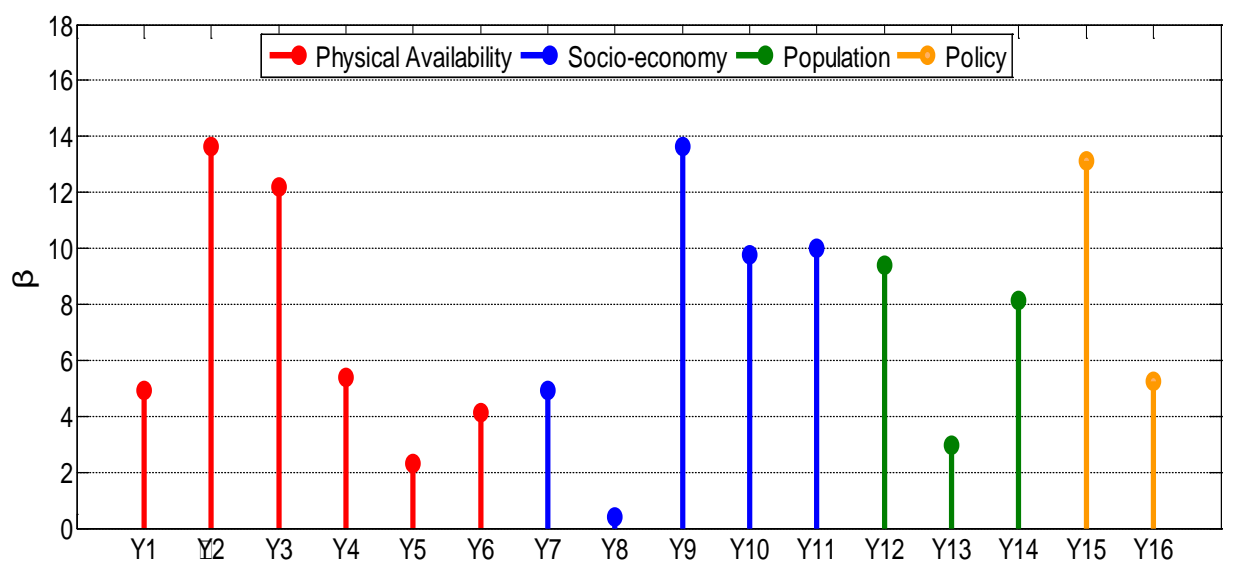

Figure 1: Values of $\beta$ for 16 factors

In this figure, the value of $Y_{2}, Y_{9}$ and $Y_{15}$ is the highest among these values.

\subsection{Sensitivity Analysis}

In the above context, we determine the region ability evaluation model as Model 1 . In the following context, we will take the first one of those comprehensive Indexes as an example to make specific Sensitivity analysis[4]. In the previous analysis, we get an equation about $Z_{1}$ : 


$$
Z_{1}=P_{1}\left(w_{11}\left(u_{11} b_{1}+u_{21} b_{2}+\ldots+u_{61} b_{6}\right)+w_{12}\left(u_{12} b_{1}+u_{22} b_{2}+\ldots+u_{62} b_{6}\right)+w_{13}\left(u_{13} b_{1}+u_{23} b_{2}+\ldots+u_{63} b_{6}\right)\right)
$$

Where $Z_{1}$ is the final score when we only take the first comprehensive index into consideration. The argument parameters $\left\{b_{i}\right\}_{i=1}^{6}$ are the specific data got from evaluation index $\left\{Y_{i}\right\}_{i=1}^{6}$ which have passed standardization process.

According to Eq. (2), the sensitivity indices of the argument parameter $\left\{b_{i}\right\}_{i=1}^{6}$ can be figured out by the following equation:

$$
\begin{gathered}
S I_{b_{i}}=\left|\frac{\partial Z_{1}}{\partial b_{i}}\right| \bullet \frac{b_{i}}{Z_{1}} \quad(i=1,2, \ldots 6) \\
S I_{Y_{i}}=S I_{b_{i}} \quad(i=1,2, \ldots 6)
\end{gathered}
$$

The higher the sensitivity index of the argument parameter $\left\{b_{i}\right\}_{i=1}^{6}$ is, the greater the influence on final score $Z_{1}$ is , and vice visa.

Using (2), (3), (4), we can calculate the sensitivity indexes of $Y_{i}(i=1,2, \ldots 6)$ by the following equation:

$$
S I_{Y_{i}}=P_{1}\left(w_{11} u_{i 1}+w_{12} u_{i 2}+w_{13} u_{i 6}\right) b / Z_{1} \quad(i=1,2, \ldots 6)
$$

Taking the measured data into (5), finally, we can calculated average sensitivity indices of all $Y_{i}$ $(i=1,2, \ldots 6)$.And the result was show in Tabel 2.

Table 2: Average sensitivity indexes of all $Y_{i}(i=1,2, \ldots 6)$

\begin{tabular}{l|l|l|l|l|l}
\hline$\overline{S I_{Y_{1}}}$ & $\overline{S I_{Y_{2}}}$ & $\overline{S I_{Y_{3}}}$ & $\overline{S I_{Y_{4}}}$ & $\overline{S I_{Y_{5}}}$ & $\overline{S I_{Y_{6}}}$ \\
\hline 0.0489 & 0.0645 & 0.0628 & 0.0511 & 0.0222 & 0.0331 \\
\hline
\end{tabular}

Compare Figure 1 with Table 2, we can find out the value of $\overline{S I_{Y_{1}}}-\overline{S I_{Y_{6}}}$ and $\left\{b_{i}\right\}_{i=1}^{6}$ shares the almost the same variation trend. This further indicate the significant influence of $Y_{2}, Y_{3}$ on index $\mathrm{Z}$.

\section{Conclusion}

\subsection{Influential Causes of Scarcity}

From the Fig.1 above, we can draw the conclusion that the most influential factors in affecting index Z in Xinjiang are cultivated land, Surface water and groundwater produced internally and policy on water dispatch.

- Cultivated land: Water consumption for agriculture accounts for great portion in total water use. Xinjiang has long been a major area of irrigated agriculture. While the low efficiency irrigation has long been a main source of water wasting, playing a large part in water scarcity in Xinjiang.

- Surface water and groundwater produced internally: Xinjiang has a semi-arid or desert climate, and it lies inland far from ocean, thus creating an extreme drying climate. This not only results in small amount of rainfall but also little resources in surface water and ground water. These are in nature caused by water circulation.

- Policy on water dispatch: Fortunately, China initiates several water resources dispatch projects like South-to-North Water Diversion Project or Tibet-to-Xinjiang Water Diversion Project.

\subsection{Physical Scarcity and Economic scarcity}


Physical scarcity (absolute scarcity), simply means natural limitation of water resources. It usually refers to those natural drivers, including water circulation, extreme climate.

Economic scarcity means the scarcity resulting from lack of investment in infrastructure when there are sufficient water resources. Usually refers to human or social factors.

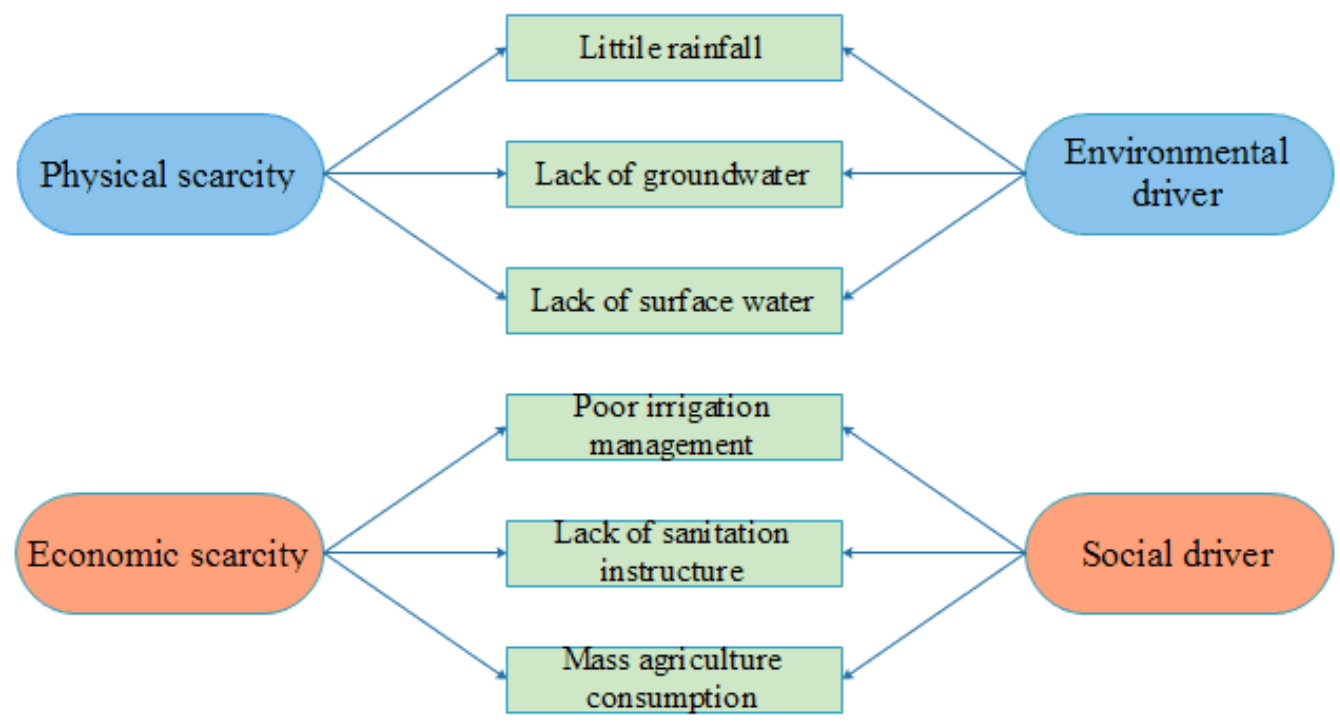

Figure 2 : The relation between physical/economic scarcity and environmental/social driver The Fig.2 explains which scarcity type and drivers these causes are from.

\section{References}

[1] Gleick, P.H. (2009), “China and water”, in Gleick, P.H. (Ed.),The World's Water, 2008-2009, Island Press, Washington, DC, pp. 79-97.

[2] Water resources in Xinjiang. National Bureau of Statistics of China. [Online]. Available: http://www.stats.gov.cn/english/Statisticaldata/AnnualData/

[3] Shoukui Ci, Xijing Sun. Mathematical modeling algorithm and application[M]. National defence industry press, 2011.

[4] Wei Cheng, Ke Li, Zhixue Wang, "Sensitivity Analysis of The Quality Evalution Model of Honeysuckle”. Shandong Science 24.5(2011):5-9. 